\title{
Measuring and Managing the Satisfaction-Loyalty-Performance Links at Volvo
}

\author{
Anders Gustafsson \\ Associate Professor of Business Economics, Service Research Center, Karlstad University, Sweden \\ Michael D. Johnson \\ D. Maynard Phelps Collegiate Professor of Business Administration and Professor of Marketing, \\ University of Michigan Business School
}

Abstract In this paper a general framework is developed for linking measures from quality to business performance via customer satisfaction and loyalty. The authors illustrate how the framework has been applied at Volvo Car Corporation. The example shows that it is possible to establish where a company should focus its improvement efforts in order to make it pay off. In this example Volvo gains a greater number of loyal customers who spend more money with the company.

\section{INTRODUCTION}

Too often companies move from one strategic initiative to another with little consideration of their natural progression. Such has been the case for many companies that have moved from an emphasis on quality in the 1980s, to customer satisfaction in the early 1990s, to customer loyalty and retention today. Managers proclaim that they have moved beyond quality and customer satisfaction to focus on what really matters, namely loyalty and profitability. In fact, there is no such thing as moving beyond quality and satisfaction. They are essential building blocks toward building loyalty and a valuable business organisation. Rather, it is essential to understand the complex links from internal quality, to external perceptions of quality and satisfaction, to loyalty and retention, and eventually to the cost savings and revenue generated.

The evolution from a quality' orientation to a customer orientation at Volvo typifies the challenges faced by companies within an intensely competitive market. Volvo has made tremendous strides in recent years to move from being an engineering-driven Swedish company to a more customeroriented global

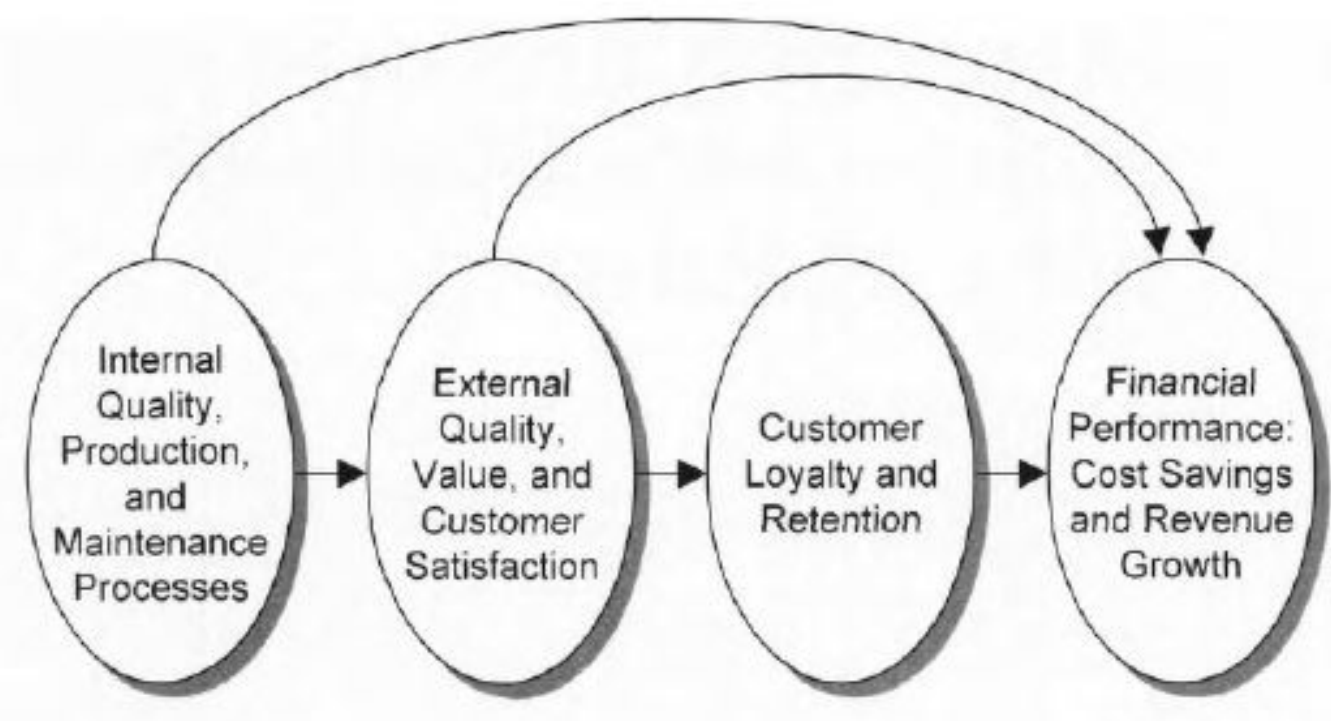


player. Yet much of this evolution has been based on a faith that doing right by the customer will ultimately pay off. The goal of this paper is to describe Volvo's challenges in moving to the next stage of evolution. This requires more precise estimates of 'exactly what' Volvo gains by increasing quality and customer satisfaction. It also requires a framework for managing the satisfaction and loyalty process.

The study contributes to the quality and satisfaction literature in two ways. First, a general framework is developed for measuring the links from quality through to business performance. The framework recognises both the direct and indirect effect of performance drivers. The framework is thus more comprehensive than those previously developed in the quality and satisfaction literature. A particular performance model is developed for Volvo as a special case of the more general framework to illustrate the approach. Secondly, by viewing performance as a bundle of desired customer behaviours, the specific effects of satisfaction and loyalty on multiple performance activities are measured. The paper begins with a description of the framework and the evolution of a customer orientation at Volvo. An empirical study is then presented to estimate the links from quality through to performance. The paper ends with implications based on the results.

\section{A FRAMEWORK FOR LINKING QUALITY, SATISFACTION, LOYALTY AND PERFORMANCE}

The general framework is presented in Figure 1. The framework incorporates four general constructs: internal quality, external or customer perceptions of quality and satisfaction, customer loyalty and firm performance measures. The first area encompasses internal quality and its varied production and maintenance processes. In the case of a manufactured product, this includes everything from manufacturing processes to the physical characteristics and attributes that describe the product. In a service and retailing context, this includes the service offer, the physical surroundings, the satisfaction of employees and the resulting service quality they provide.

The second area encompasses external or customer-based perceptions of the purchase and consumption experience. This includes customer perceptions of the attributes and benefits that products and services provide, the costs incurred and customers' overall evaluations of the product, service or provider (customer satisfaction). The third area includes customer loyalty and retention. Loyalty is a customer's intention or predisposition to buy, while retention is whether the intended behaviour actually occurs (as when a customer returns to a restaurant, comes back to buy the same brand of car, or purchases another financial instrument from the same institution). Although the term 'loyalty' is used at times to encompass both intended loyalty and actual retention, it is important to understand the distinction. When actual retention information is available, it proves extremely valuable in sorting out the drivers of financial performance. When it is unavailable, loyalty measures are typically used as a proxy for retention.

Quality, satisfaction and loyalty ultimately affect costs and revenues. The framework highlights both the direct and indirect effects that these areas have on financial performance. The effects of internal quality are considered first. Producing a high quality product or service at an attractive price directly affects external customer perceptions of the purchase-consumption experience. But internal quality may also have a direct effect on costs and revenues. Improvements in internal quality may increase productivity and lower internal costs and thus directly increase profitability. Research suggests, however, that this link is more likely to be positive for products and smaller, if not negative, for services.' Services are produced and delivered at a time and place that is typically dictated by the customer. Thus, improving service 
quality often requires an increase in personnel and operating or contact hours, which raise operating costs.

The external quality, value and customer satisfaction component of the framework, also has direct as well as indirect effects on costs and revenues. Indirectly, a positive overall experience predisposes customers to stay loyal towards a product, service, or provider, which generates future sales. Satisfaction thus contributes to financial performance through its effect on loyalty and retention. A positive purchase and consumption experience also has a direct effect on revenue generation and cost reduction that is independent of loyalty per se. The cost of maintaining a customer account, or fixing a product, is a direct function of how happy the customer is. Satisfied customers are less likely to demand expensive product repairs or replacements or invoke service guarantees. Positive (versus negative) customer referrals and word-of-mouth are also a direct function of perceived quality and satisfaction rather than loyalty per sc.

Finally, the direct effect of loyalty and retention on performance captures a variety of retentionrelated factors, including the base revenues from repeat purchases, a reduction in the costs required to acquire new customers (to replace lost customers), and revenues generated through cross-selling. It also includes the price premium that loyal customers often pay. Because loyalty customers are not actively shopping for alternatives, they tend to be insulated from price incentives and offers such as coupons, price cuts and free merchandise.

Central to the framework is the idea that loyalty is one link within an overall loyalty management chain that runs from internal quality through to profitability. Loyalty cannot be managed in isolation to the exclusion of internal quality and satisfaction. An analysis of customer defects typically reveals sources of dissatisfaction and quality problems. In the end, loyalty can only be built on a sound foundation of high-quality products and services and satisfied customers."1 For long-term survival a good quality foundation is essential but it is not in itself sufficient. The quality efforts must be linked to improvements in external quality, satisfaction, loyalty and financial performance. And the links must be established in an environment of' constantly evolving customers, markets, competitors and technologies.

Another feature of the framework is that by ignoring the building blocks of a loyalty programme, the direct effects of quality and satisfaction may be overlooked. As is shown later, satisfaction is profitable independent of its impact on loyalty. Likewise, quality can lead directly to profitability.

\section{TURNING VOLVO AROUND}

In 1991 Volvo was struggling for survival. Despite improved business year by year Volvo was losing ground in the J. D. Power measurement system. The simple fact was that its competitors were improving much faster. When Volvo reached 26th place out of 34 car brands, making customers a priority became a singular strategy for survival in the intensely competitive global motor industry.

The efforts are known to have worked, otherwise Ford Motor Company would not have paid 50bn Swedish Kroner (SEK) for Volvo in 1999. In 1991, the question for Volvo was how to create a customer orientation in a traditionally engineering-driven company. The efforts can be summarised under six headings:

- implementing extensive total quality management (TQM) programmes: this was necessary in order to achieve a higher degree of commitment from the employees. TQM programmes also help align the organisation, making it work to achieve common goals 
- breaking down visions and goals into targets at a very detailed level, which is commonly called policy deployment or hoshin kanri. Volvo's vision is 'To be the worlds most desired and successful specialty car brand'. To be able to reach this, over 2,000 potential areas for improvement were identified, and quality teams were formed to focus on the 200 highest priority areas

- altering Volvo's view of the company, focusing on processes instead of functions, ie implementing process management. Previously, cars were sold down the chain from the plant to the marketing department, the importer, the sales company and, finally, to the dealer. This needed to be replaced by a holistic view embracing the entire chain from Volvo management in Sweden and the USA all the way to the customer

- widening the scope when viewing the customers: Volvo realised that trouble-free ownership is a function of much more than the production process

- a culture of openness. Employees perceived that the company must be doing quite well since

they were improving year by year. The truth was rather the opposite and the employees needed to know about this. Volvo consequently abandoned its 'hush-hush' approach to quality and customer data

- measurement system for customer satisfaction, including the development of a complete measurement system covering all aspects of buying and owning a car.

Volvo has done very well in a number of areas and has received a lot of recognition for that. For instance, David Power, founder of J. D. Power \& Associates has, on a number of occasions, commented that no other automaker has improved its performance at the same rate as Volvo. In this context, improvement is a matter of attention to thousands of measurable and detailed activities by thousands of people throughout the Volvo organisation, all with a common commitment to customer satisfaction.

After going through this extensive improvement programme Volvo felt a need for new ways of establishing what is important to their customers. The cars that are produced today are becoming better and better and thus more equal in terms of reliability, durability and such. The key to gaining competitive advantage is to determine what improvements will affect the customers' perception of the car. Volvo's measurement system is simply not sensitive enough. Furthermore, after years of creating and sustaining a commitment to increasing quality and satisfaction, executives at Volvo began to look for proof that their approach was having an effect on the bottom line. It was not enough that the quality'-satisfaction- loyalty logic helped them to 'sell' a customer orientation throughout the organisation - they wanted to prove it. They also wanted to calculate just how much money they make by improving their quality'. It is in the light of this that the following sections should be read.

\section{ESTABLISHING A QUALITY-SATISFACTION-LOYALTY-PROFIT MODEL AT VOLVO}

Volvo have three different satisfaction studies regarding customers in Sweden that are carried out on a regular basis. These surveys measure customer satisfaction with the dealer, with the vehicle after two months of ownership, and with the workshop or service process. The database that the authors had access to included information on approximately 25,000 individual customers who had bought a Volvo in 1993 and a new car again in 1997. The database is unique in that it contains information for some customers on, for instance, whether the second vehicle purchased was another Volvo, whether they used Volvo financing, had Volvo insurance, possessed a Volvo charge card, and how much money they charged to their card. 
Figure 2 illustrates how the framework in Figure 1 was applied to the analysis of the different satisfaction data sets. It illustrates a network of relationships in which various quality' drivers affect satisfaction with the sales, workshop and vehicle experience. These three sources of satisfaction or benefits then drive the customers' overall satisfaction and subsequent loyalty intentions (or stated loyalty). The customers' actual behaviour, however, is a function of both stated loyalty and overall satisfaction. The aim was to perform the analysis in one step. But as it turned out, data limitations prevented the authors from estimating all of the relationships using a single analysis. As an alternative, they carried out the analyses for each survey separately (ie a separate analysis for the sales, the workshop and the car).

The analysis worked quite well and the authors managed to establish the links from the drivers to different behaviour. Figure 3 is one primitive illustration of this. The figure shows the level of stated loyalty for the group of respondents who have actually been loyal compared to the ones who have switched. For the car it actually seems to work; respondents who clearly stated that they would buy

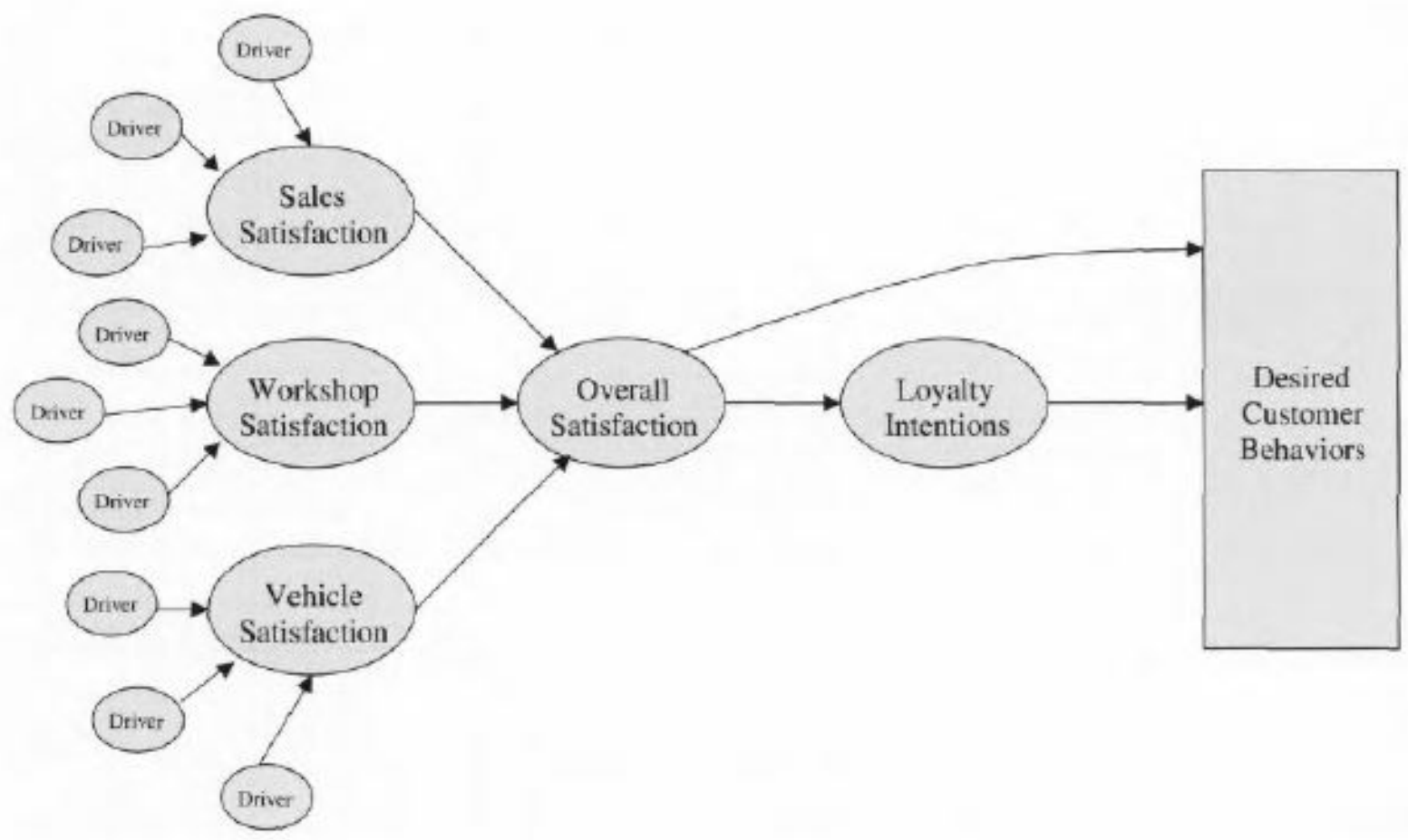

another Volvo have done that, to a large extent. But it is also found that a high level of stated loyalty for the car dealer does not automatically mean that the respondents actually do go back to the same dealer again. The relationship is not that simple. The next section starts to show some of the complexity when the links between quality, satisfaction, loyalty and profits are studied.

\section{FINANCIAL LINKS FOR VOLVO}

The focus in this section is on the analysis conducted using the sales satisfaction survey. The number of respondents for whom the authors could access data on how good the deal was for Volvo was limited. There was only one retailer chain that could calculate profit per car; luckily it was the 
largest chain in Sweden with 40 per cent of the total market for Volvo cars. A sample of customers was extracted from the database $(n=393)$, customers truly loyal

in that they not only bought another Volvo; they even bought it from the same car dealer. It is natural to assume that these customers were relatively satisfied with their previous experience, as can be seen from the satisfaction index for sales ( 8.73 for this sample compared to 8.56 for the total population in the database based on a 1 to 10 scale). It is also known that this class of customers is not the one improvement efforts should be aimed at since the pay-off is relatively low. These customers are extremely satisfied and are likely to go back and spend money at Volvo even if Volvo does not improve.

Partial least squares (PLS) were used to analyse the data. PLS is used to predict a pattern of relationships and effects within an overall network. The models also contain latent or unobservable variables such as satisfaction, and loyalty. Scientifically, these variables are only measurable indirectly using multiple concrete proxies. Furthermore, the data in satisfaction studies are usually extremely skewed. Finally, the aim is to explain what drives behaviour in a causal sense. PLS is well suited for the constraints.

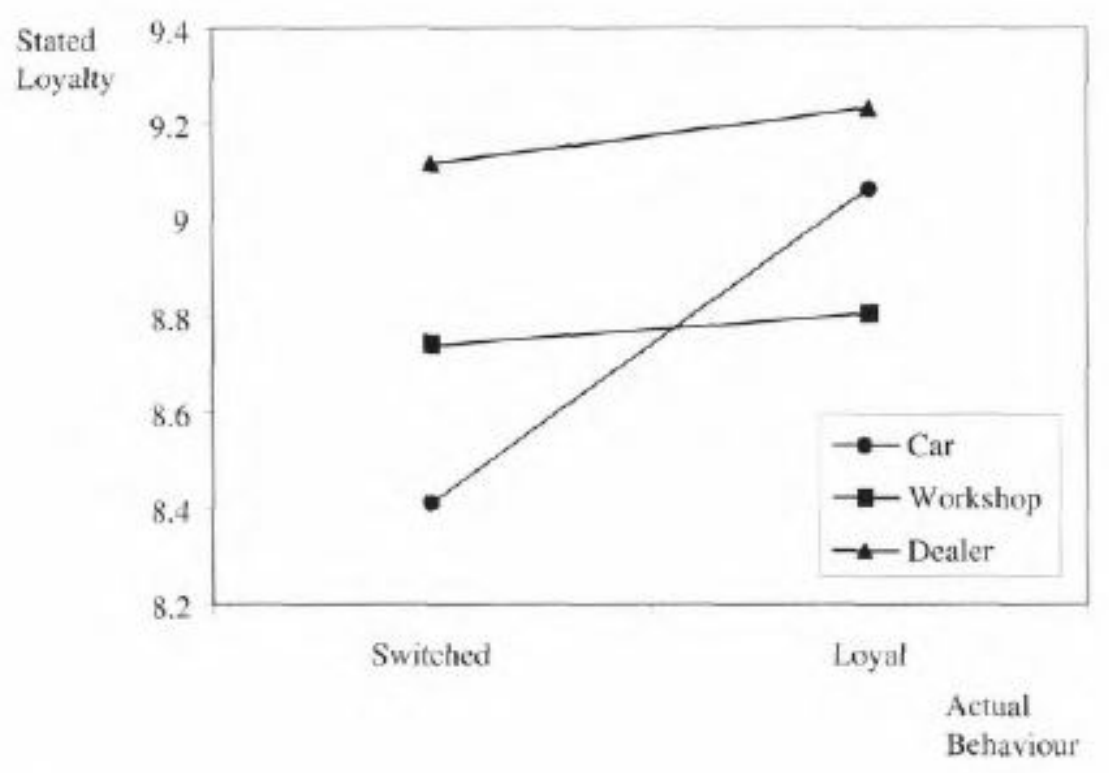

Figure 3 Levels of stated loyalty linked to actual behaviour

Figure 4 presents results from the analysis. The circles to the left in the figure represent benefit areas measured as latent variables from the questionnaire. The variables to the right represent different behaviours (possession of a Volvo card, financing with Volvo and so on). The numbers within the circles are the performance level indices for the drivers of satisfaction, and the numbers on the arrows represent the impacts.

Performance of the vehicle (very' early in the consumption experience) has the highest impact on satisfaction followed by the performance of the personnel and vehicle delivery respectively. The impact of satisfaction on stated loyalty at the time of the survey is 0.410 . Typically, stated loyalty should affect subsequent customer behaviours and profit. The authors found, however, that stated loyalty' had no impact on profit in this case. The loyalty' measures in this case are simply collected too early in the 
purchase-consumption-repurchase cycle (shortly after delivery'). It is difficult for customers to reflect on their future buying plans and state whether they will buy another Volvo. What is interesting, however, is that overall satisfaction even early in the consumption experience has a very significant and positive impact on profit per customer on the next vehicle purchased.

Volvo managers also wanted to understand how many of the other services they provide for customers have an effect on the money spent on the next purchase. The model results show, for example, that it a customer uses the Volvo card, it has a significant impact on future profit. Volvo has been successful in providing a financial service through its card, by which the customer can divide any charge into four payments without incurring any additional costs. It may be surprising to find that financing has a negative effect on profit. The explanation is that salespeople often give customers who finance their car through Volvo a better price knowing that the company will make more money on the total package.

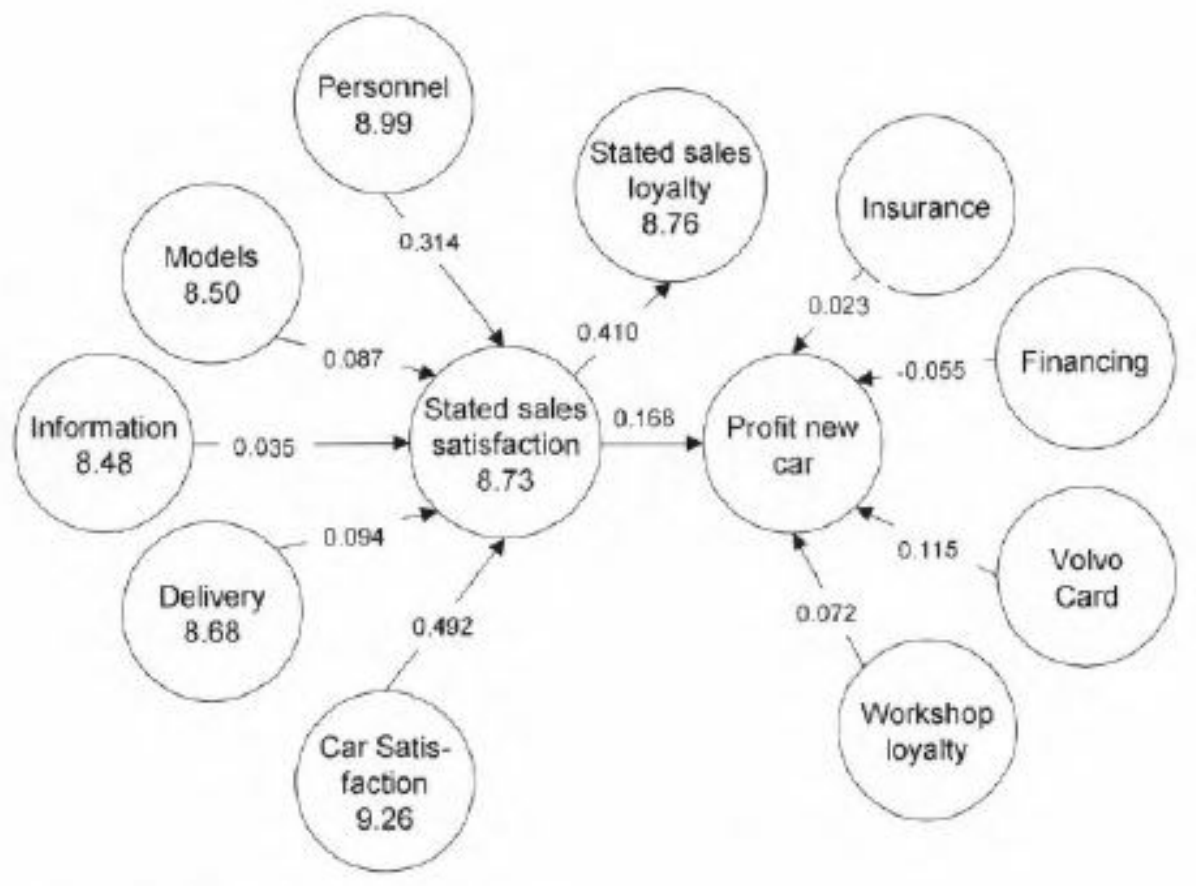

Figure 4 Sales satisfaction model for Volvo dealers

The profit impact of quality improvement in the sales process was then estimated. The 'what if analysis asks, 'what happens if a customer's perception of the sales process improves by one scale point in the survey?' A PLS analysis of the data provides the weights and loadings required to calculate the impact on profit. The results are shown in Table 1. The effects of the vehicle performance were calculated in a separate analysis.

It was found that if the Volvo dealers improve their quality one-scale point on each of the four areas in the table (based on one to ten-point performance scales), they gain roughly 4 per cent more profit downstream at the next purchase. They gain most by improving personnel (almost 3 per cent). Although not shown here, it is possible to break this effect down into improvements on specific attributes of the customer-salesperson interaction. The analysis provides a flavour of the types of impacts that can be determined when survey data and profit per customer data are combined. It must, however, be acknowledged that the results are a snapshot in time ot a particular company's customer 
base. And the customers that the model is valid for are the most loyal customers at a certain car dealer. Nevertheless, among the more interesting points in the case is that the customer data, which are collected up to three years before the sale of the next vehicle, predict significant, positive effects on future profit.

\section{DISCUSSION}

Volvo Car Corporation went through quite dramatic changes in the 1990s and competition in the car industry is getting harder. The cars are becoming more and more equal in terms of reliability figures, safety features and initial quality leading the authors to believe that companies will need to compete in areas other than the hardware. In order to do that, Volvo needs to evolve from being just an engineering-driven Swedish company to a more customer-oriented global competitor. One tool in this process is a sensitive measurement system that will help Volvo guide its improvement efforts to areas with the highest pay-offs in terms of a greater number of loyal customers who spend more money at Volvo.

Table 1 Estimated return on quality improvements in the sales process

\begin{tabular}{ll}
\hline Latent variable & $\%$ of net \\
\hline Personnel & 2.7 \\
Available models & 0.5 \\
Information & 0.2 \\
Delivery & 0.6 \\
\hline
\end{tabular}

In the example used in this paper it was shown that Volvo Car Corporation could increase its profits by 4 per cent by improving its sales performance with one scale point (based on one to ten-point performance scales). The authors have also done similar calculations for the car itself. It turned out that one-scale step improvement on the car was worth an increase in profits of roughly 10 per cent. While no significant increase of profits with increased satisfaction was found for the workshop. This makes perfect sense because no-one buys a car just for the sake of repairing it. No matter how satisfied customers are, they do not go to the workshop and ask for repairs that are unnecessary. For the workshop, however, it can be seen just how vital the Volvo card is in enticing customers to come back. Even if customers do not spend more money at the workshop because they are satisfied, a good workshop is a must in order to get customers to return at all. What is also found in the analysis is that a good workshop strengthens the dealer, and makes customers more prone to come back and buy a new car.

The fact that there are some aspects that can be regarded as must-be-qualities leads to another discussion regarding what this analysis captures. The effects estimated in the analysis are the relative importance of each latent variable as revealed by its statistical impact on overall satisfaction, ie an aspect only emerges as important if there is variation in the variables. Even if a latent variable does not have a large impact on satisfaction, loyalty and profits, the aspect may still be important for customers. In the well-known Kano model these are called basic or must-be-quality attributes. The basic attributes are those performance dimensions that customers take for granted. They are presumed to have little impact on satisfaction, unless of course a company fails to provide them in which case the impact on dissatisfaction is huge. Parallels to this can be made about the workshop. 
In the example the authors have chosen not to go into detail and illustrate specific actions that Volvo could take in order to earn more money. They have shown that Volvo could earn roughly 3 per cent more if the performance of personnel improved with one scale step. It is possible to go into more detail and look at which specific item of personnel performance has the highest impact on profits. For instance, in this case one of the questions with one of the highest pay-offs was 'How reliable was the sales personnel at the sale of the car'?

In the case used to illustrate the framework, it was interesting to find that early measures of satisfaction actually worked as predictors for future profits. The sales satisfaction measures were collected two months after the actual sale and the profit estimates were calculated three years after the next purchase. This is especially interesting now that it is found that lead times in the product development processes are decreasing rapidly. In the 1970s and 1980s a car model could last ten to 15 years with only minor modifications year by year. This is not possible today. One of the future challenges is to understand just how early it is possible to collect data on what drives customer satisfaction and still receive useful information in order to improve the product. Ideally, the customers would have used the product for some time, maybe two to three years in the case of a car. Given that the average lifetime of a new car model at Volvo is three to four years such feedback would be of limited use. 


\section{References}

1 Johnson, M. D. (1998) 'Customer orientation and market action', Prentice Hall, Upper Saddle 1-Liver, NJ.

2 Johnson, M., Herrmann, A., Huber, F. and Gustafsson, A. (1997) 'Customer retention in automotive industry", Gabler, Wiesbaden.

3 Johnson, M. D. and Gustafsson, A. (2000)

'Improving customer satisfaction, loyalty and profit: An integrated measurement and management system", Jossey-Bass. San Francisco.

4 Flodin, S., Nelson, T. and Gustafsson, A. (1997) 'Improved customer satisfaction is a Volvo priority', in Johnson, M. D., Herrmann, A., Huber, F. and Gustafsson A. (eds) 'Customer retention in the automotive industry: Quality, satisfaction and loyalty'. Gabler, Wiesbaden, Germany.

5 Gustafsson, A., Ekdahl, F., Falk, K. and Johnsson, M. F). (2000) 'Linking satisfaction to design - A key to success tor Volvo", Quality Management Journal, Vol. 7, No. 1, pp. 27-38.

6 Johnson and Gustafsson (2000) op. cit.

7 Fluff, L., Fornell, C. and Anderson, E. (1996) 'Quality and productivity: Contradictory and complementary", Quality Management Journal. Vol. 4, No. 1, pp. 22-39.

8 Edvardsson, 13., Johnson, M. 1)., Gustafsson, A. and Strandvik, T. (2000) 'The effects of satisfaction and loyalty on profits and growth - Products versus services', Total Quality Management, Vol. 11, No. 7, pp. 917-927.

9 Johnson and Gustafsson (2000) op. cit.

10 lbid.

11 Flodin, Nelson and Gustafsson (1997) op. cit.

12 Auh, S. and Johnson, M. D. (1997) 'The complex relationship between customer satisfaction and loyalty for automobiles', in Johnson, M. D., Herrmann, A., Huber, F. and Gustafsson, A. (eds) 'Customer retention in the automotive industry: Quality, satisfaction and loyalty', Gabler, Wiesbaden, Germany.

13 Gustafsson, A. and Johnson, M. D. (1997) 'Bridging the quality-satisfaction gap". Quality Management Journal, Vol. 4, No. 3, pp. 27-43.

14 Steenkamp, J-B. E. M. and van Trijp, H. C. M. (1996) 'Quality guidance: A consumer-based approach to food quality improvement using partial least squares", European Review of Agricultural Economics, Vol. 23, pp. 195-215.

15 Kano, N. (1995) 'Upsizing the organisation by attractive quality creation'. Total quality management - Proceedings of the first world congress'. Kanji, G. K. (ed.) Chapman \&: Hall, London, pp. 6072.

16 Kano, N., Seraku, N., Takahashi, F. and Tsuji, S. (1984) 'Attractive quality and must-be quality", Hiushitsu, Vol. 14, No. 2, pp. 147-156, (in Japanese). 